\title{
Effects of spatial variability of nitrogen supply on environmentally acceptable nitrogen fertilizer application rates to arable crops
}

\author{
M. VAN NOORDWIJK \& W.P. WADMAN
}

DLO-Institute for Soil Fertility Research (IB-DLO), P.O. Box 30003, NL 9750 RA Haren, Netherlands

Received: 24 September 1991; accepted: 13 December 1991

\begin{abstract}
Current $\mathrm{N}$ recommendation schemes are based on the Maximum Economic Yield (MEY), as obtained at 'economic optimum' fertilizer application rates. Environmental standards for the amount of mineral $\mathrm{N}$ left in the soil at harvest time will soon restrict fertilizer rates to obtain an Environmentally Acceptable Production (EAP). For MEY, but especially for EAP, spatial variability of $\mathrm{N}$ supply in a field which is managed as if it were a homogeneous unit should be taken into account. A model is presented here, based on a four-quadrant representation of $\mathrm{N}$ fertilizer experiments. Effects of spatial variability of various terms of the N-balance were investigated in the model. Calculations showed that spatial variability of mineral-N supply in the soil leads to higher 'economic optimum' fertilizer rates, while the rates which are allowed for EAP decrease. For a standard set of parameters, but without spatial variability, a positive difference of $13 \mathrm{~kg}$ per ha exists between the $\mathrm{N}$ fertilizer rates for EAP and MEY, even if the strictest environmental standard is applied (soil mineral $\mathrm{N}$ content at harvest is not allowed to exceed $34 \mathrm{~kg} \mathrm{ha}^{-1}$ ). At standard levels of variability a negative difference of $26 \mathrm{~kg} \mathrm{ha}^{-1}$ was calculated and at doubled variability this difference was $156 \mathrm{~kg} \mathrm{ha}^{-1}$. An $\mathrm{N}$ residue at harvest of $45 \mathrm{~kg} \mathrm{ha}^{-1}$ can be met at standard variability, but not at doubled variability. The model shows that higher degrees of 'luxury consumption' and improved synchronization of mineralization and crop demand have a positive effect on the difference between EAP and MEY. The choice for relatively homogeneous sites for field experiments has introduced a bias in existing quantitative data on environmental effects and crop response to fertilizer application. We conclude that the degree of spatial variability in $\mathrm{N}$ supply should be explicitly taken into account in future discussions of the conflict between environmental and production targets.
\end{abstract}

Keywords: crop yield, fertilizer nitrogen, nitrogen fertilizer recommendation, price ratio, residual soil mineral nitrogen, simulation model, spatial variability

\section{Introduction}

Conventionally, $\mathrm{N}$ recommendation schemes have been based on the Maximum Economic Yield (MEY), as obtained at 'economic optimum' fertilizer application rates (Neeteson, 1990). Environmental standards will soon restrict fertilizer rates to obtain an Environmentally Acceptable Production (EAP). For the present 
discussion we will assume that $\mathrm{N}$ fertilizer use is environmentally acceptable if leaching losses are less than standards based on drinking water quality. In climates such as found in the Netherlands, where leaching mainly occurs after the growing season, the amount of soil mineral $\mathrm{N}$ at harvest time, i.e. residual soil mineral $\mathrm{N}$, can be used as criterion for EAP.

No problems exist if the $\mathrm{N}$ fertilizer rate acceptable for $\mathrm{EAP}$ is much larger than the one required for MEY $\left(\mathrm{N}_{\mathrm{EAP}}>>\mathrm{N}_{\mathrm{MEY}}\right)$. If $\mathrm{N}_{\mathrm{EAP}}<\mathrm{N}_{\mathrm{MEY}}$, a conflict between production and environmental aims exists. In the past this meant environmental pollution, in the near future this wil mean reduced production. If the difference $\mathrm{N}_{\text {EAP }}-\mathrm{N}_{\text {MEY }}$ is positive but narrow, a farmer will need a very precise knowledge of the $\mathrm{N}$ supply by mineralization to apply the right amount of fertilizer $\mathrm{N}$. Given a certain amount of organic inputs to the soil, a considerable year-to-year variation exists in $\mathrm{N}$ mineralization, mainly due to differences in temperature and soil water content. The year-to-year variation in crop $\mathrm{N}$ demand is smaller and is probably partly correlated with mineralization. Split application of fertilizer and an intensive crop-monitoring scheme can (in future) compensate for part of this year-to-year variability. Still, a difference between $\mathrm{N}_{\mathrm{EAP}}$ and $\mathrm{N}_{\mathrm{MEY}}$ of at least 20 $\mathrm{kg} \mathrm{ha}^{-1}$ seems necessary to cope with this uncertainty, even when the best sitespecific fertilizer recommendation scheme is followed, to meet environmental standards (almost) every year and not only in average years.

Based on public health standards for drinking water, average leaching rates in the Netherlands and the assumption of no losses by denitrification, it can be calculated that the amount of residual mineral $\mathrm{N}$ in the rooted zone in autumn may not exceed $34 \mathrm{~kg} \mathrm{ha}^{-1}$. For crops harvested early a catch crop can partly recover $\mathrm{N}$ residues left by the main crop, but net mineralization will continue after harvest of the main crop. For the present discussion we take the $\mathrm{N}$ residue at harvest of the main crop as a basis for environmental standards. Because at least some denitrification may be expected standards of 45 and $70 \mathrm{~kg} \mathrm{ha}^{-1}$ are currently considered as a basis for policy decisions (Neeteson, 1992).

The crop response to nitrogen fertilizer in field trials typically follows a Mitscherlich-type curve, with a very slow approach to the maximum yield (Figure 1). Most pot experiments and process-oriented models, however, suggest a more rapid approach to the maximum production. Dahnke \& Olson (1990) showed that the combination of a number of linear-plateau responses ('broken stick' models), with variable slopes in the linear phase and variable plateau values, will result in a Mitscherlich-type response. Curnow (1973) showed how a smooth population response curve can be based on normally-distributed values for a response threshold for individuals. An alternative interpretation of these results is that the response of all individuals in the population is the same, but that their environment is not uniform.

Figure 2 shows the effect of variability in $\mathrm{N}$ supply for a simple yield-response model, based on the ascending branch of a quadratic equation. Increasing variability has a relatively small effect in the range where yield is severely depressed by $\mathrm{N}$ shortages, but it has a large effect on the average $\mathrm{N}$ supply needed for near-maximum yields. 


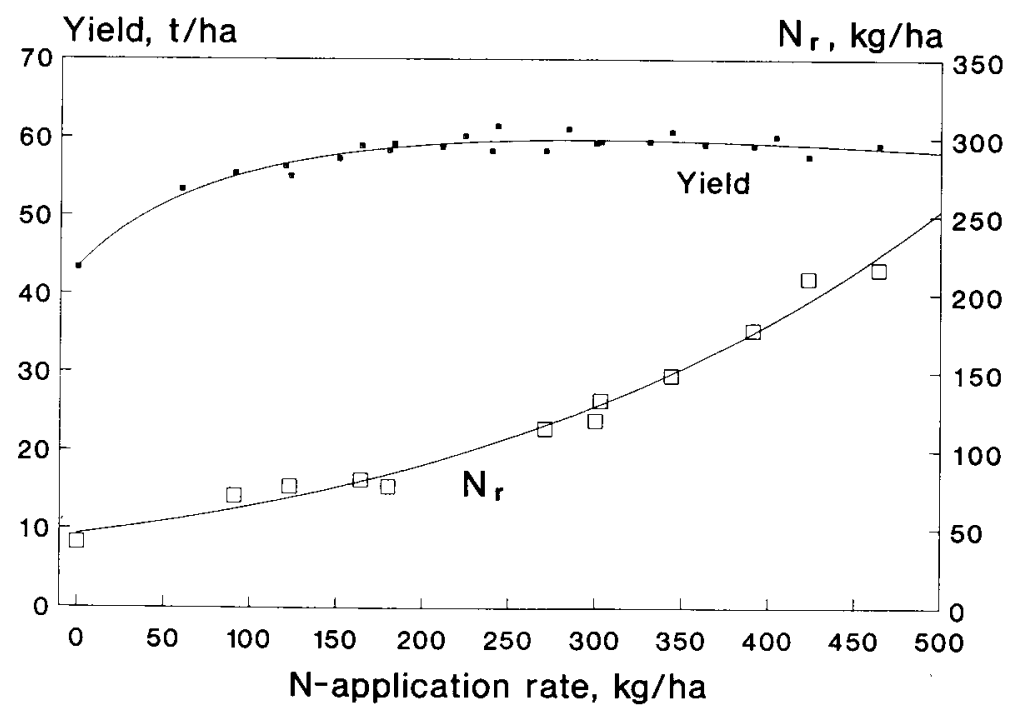

Fig. 1. Influence of $\mathrm{N}$-fertilizer rate on yield of starch potatoes and on residual mineral nitrogen, $\mathrm{N}_{\mathrm{r}}$, at harvest time; summary of recent Dutch fertilizer trials (Neeteson, 1992).

\section{Yield, Mg/ha}

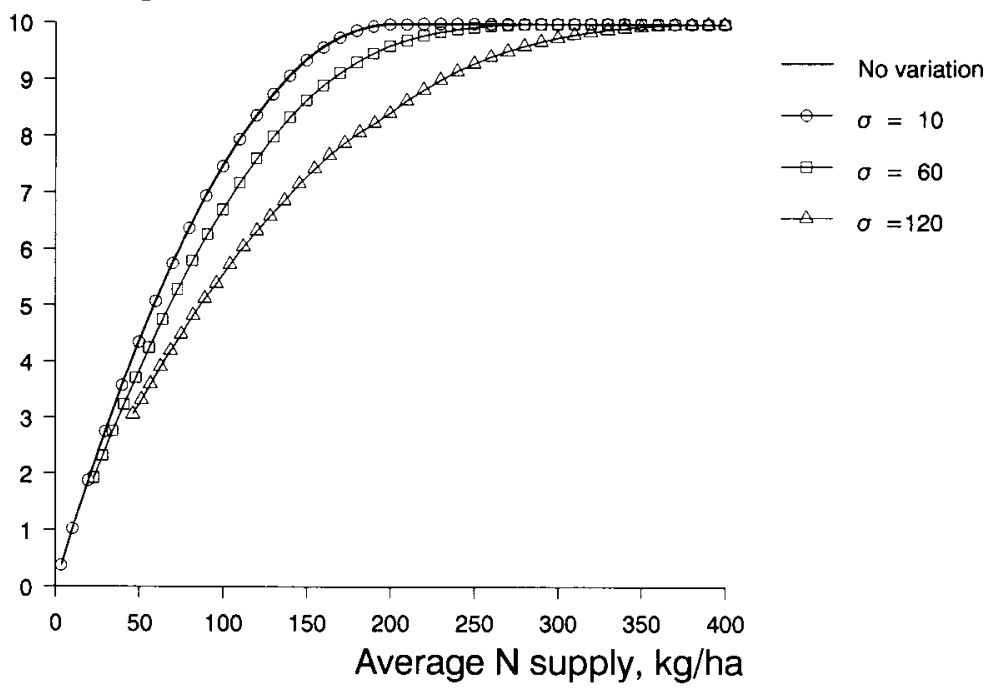

Fig. 2. Effect of variability in $\mathrm{N}$ supply to individual plants for a population yield response curve. For each individual, yield response is supposed to follow an ascending branch of a quadratic equation; for $\mathrm{X}<\mathrm{C} \mathrm{Y}_{\max }: \mathrm{Y}=\left(2 \mathrm{X}-\mathrm{X}^{2} /\left(\mathrm{C}_{\max }\right)\right) / \mathrm{C}$; for $\mathrm{X}>\mathrm{C} \mathrm{Y}_{\max }: \mathrm{Y}=\mathrm{Y}_{\max }$; with $\mathrm{C}=0.02 \mathrm{~kg} \mathrm{~kg}^{-1}$ and $Y_{\max }=10 \mathrm{Mg} \mathrm{ha}^{-1}$. The $\mathrm{X}$-axis represents the average value for a normal distribution of $\mathrm{N}$ supply with three values of the standard deviation $\sigma$; values for $\sigma=10 \mathrm{~kg} \mathrm{ha}^{-1}$ cannot be distinguished from those for $\sigma=0$. 
Experimental data show a certain $\mathrm{N}$ residue at harvest when no fertilizer is applied, and an increase in the residue at higher $\mathrm{N}$ fertilizer application rates, with a slowly increasing slope. In Figure 1 the slope approaches $1.0 \mathrm{~kg} \mathrm{~kg}^{-1}$. Considerable variation exists between crops and fields in three aspects of this curve: (1) the residue at 0-N application, (2) the slope of the increase in residue in the fertilizer range where a yield response occurs, and (3) the point where the residue starts to increase (almost) 1:1 with fertilizer rate. In certain situations, even without $\mathrm{N}$ fertilizer application the $\mathrm{N}$ residue at harvest exceeds the environmental standards. A summary of recent $\mathrm{N}$ fertilizer experiments (Prins et al., 1988; Neeteson, 1990) shows relatively safe crops (mown grassland, cereals, sugar beet), where $\mathrm{N}_{\mathrm{MEY}}$ is less than $\mathrm{N}_{\mathrm{EAP}}$, and problematic ones (grazed grassland, silage maize, potatoes, several vegetable crops).

The presence of substantial amounts of residual $\mathrm{N}$ at harvest at $\mathrm{N}$ fertilizer rates at which the crop still responds to $\mathrm{N}$ fertilizer may be explained by a combination of three factors:

- There usually is no complete synchronization of nitrogen supply and crop demand; especially mineralization at the end of the growing season, with decreasing $\mathrm{N}$ demand, may lead to $\mathrm{N}$ residues at harvest time; this amount may be independent of fertilizer rate.

- Transport to the roots by diffusion depends on gradients in concentration, so the soil cannot be completely exhausted in a restricted period of time. As de Willigen \& van Noordwijk (1987) showed, the amount of nutrients not available because of transport limitations depends on the apparent adsorption constant of the nutrient, on soil water content, root length density and daily crop demand.

- Spatial variability in $\mathrm{N}$ supply within a field, which is managed as if it were homogeneous; near-maximum production levels can only be achieved by increasing the average $\mathrm{N}$ supply to a level high enough for almost all plants to reach near-maximum production; this implies that most plants have more than enough. Spatial variability in $\mathrm{N}$ supply is usually the result of a combination of variable initial amounts of mineral $\mathrm{N}$ in the soil ( $\mathrm{N}_{\min }$ in spring), inhomogeneous patterns of applying $N$ fertilizer (Dilz \& van Brakel, 1985), and variable net mineralization rates during the growing season. $\mathrm{N}$ losses during the growing season, e.g. due to denitrification, are included in the net mineralization rate. Variability exists on many scales. Variability within reach of the root system of a single plant - roughly speaking within the 'unit soil area' as defined by de Willigen \& van Noordwijk (1987) - may enhance uptake efficiency if the roots are able to reach the places of high supply (synlocalization). Variability on a scale beyond the unit soil area will lead to decreased efficiency, especially at near-maximum production levels, as plants on places of relatively high supply cannot (fully) compensate for poor growth of plants at low supply. Current soil-crop models do not take spatial variability into account (de Willigen, 1991) and data on variability are not considered to be essential for model validation (Groot \& Verberne, 1991).

For a poorly buffered system as found in soilless horticulture, spatial variability and incomplete synchronization of supply and demand were identified as major 
factors responsible for the low nutrient use efficiency and high losses to the environment (van Noordwijk, 1990). In this paper we will discuss two questions for field-grown crops:

1. which factors determine $N_{E A P}, N_{M E Y}$ and the difference $N_{E A P}-N_{M E Y}$,

2. what can be done to create a sufficiently large positive difference and thus reduce the conflict between environmental and production targets in crop production.

A simple model was constructed to evaluate the interaction between the three agronomic reasons for residual $\mathrm{N}$ at harvest time and to evaluate which factor is probably dominant under normal conditions. The model is based on a fourquadrant representation of $\mathrm{N}$ fertilizer response (van Noordwijk \& de Willigen, 1986), extending the three-quadrant representation of de Wit (1953).

\section{Model description and parameters}

In a four-quadrant representation (see below, Figure 5) the relation between $\mathrm{N}$ fertilizer application rate, $N_{F}$, and crop yield, $Y_{H}$ (Quadrant II) is analysed in three steps: the relation between $N_{F}$ and the available $N$ supply during the growing season, $\mathrm{N}_{\mathrm{A}}$, (Quadrant III), the relation between $\mathrm{N}_{\mathrm{A}}$ and $\mathrm{N}$ uptake by the crop, $N_{u}$, (Quadrant IV), and the relation between $N_{U}$ and $Y_{H}$ (Quadrant I). In the three-quadrant approach of de Wit (1953), a direct relation between $N_{F}$ and $\mathrm{N}_{\mathrm{U}}$ was sought.

In Quadrant II the 'economic optimum' fertilizer application rate is usually defined as the amount of fertilizer where costs of additional fertilizer are still just met by additional productivity. When the resource use efficiency of two production systems is compared at a fixed input level, the system with the higher maximum production level will normally appear to be more efficient, especially if the input level chosen was above the absorption capacity of the less productive system. Comparisons become more meaningful if appropriate input levels for each system are chosen. A non-ambiguous definition of appropriate in this context may be based on the 'economic optimum' input level for each system. Here we will make comparisons at the economic optimum fertilizer rate for each system.

All parameters for the model are listed in Table 1 , as well as the parameters used for a 'standard' case. The model will be described here by first specifying the relations used in each quadrant and then discussing the variability of key parameters.

\section{Quadrant $I I I$, the relation between $N_{F}$ and $N_{A}$}

Available mineral $\mathrm{N}$ in the soil during the growing season, $\mathrm{N}_{\mathrm{A}}$, originates from the soil, $\mathrm{N}_{\mathrm{S}}$ and from fertilizer, $\mathrm{N}_{\mathrm{F}}$. An efficiency ratio, $\mathrm{f}_{\mathrm{a}}$, indicates which fraction of the applied nutrients is available in mineral form during the crop uptake period. Soil $\mathrm{N}$ consists of mineral $\mathrm{N}, \mathrm{N}_{\min }$, at planting time $\left(\mathrm{T}_{0}\right)$, and the integral over the net mineralization rate, $\mathrm{R}_{\mathrm{Netmin}}$, until the time of maximum $\mathrm{N}$ content of the crop, $T_{M}$. Net mineralization is the sum of mineralization, immobilization and other 
losses from mineral $\mathrm{N}$ during the growing season, including denitrification. For the standard situation we assume no temporal variation in daily net mineralization ( $R$

$$
\begin{aligned}
& =\text { constant }): \quad N_{A}=N_{S}+f_{a} N_{F} \\
& N_{S}=N_{\text {min }}+\int_{T_{0}}^{T_{M}} R_{\text {Netmin }} d t=N_{\text {min }}+R_{\text {Netmin }}\left(T_{M}-T_{0}\right)
\end{aligned}
$$

\begin{tabular}{|c|c|c|c|}
\hline Symbol & Definition & Dimension & Value \\
\hline $\mathrm{C}_{\mathrm{m}}$ & $\begin{array}{l}\text { Crop nutrient concentration for maximum pro- } \\
\text { duction }\end{array}$ & $\mathrm{g} \mathrm{g}^{-1}$ & (Eq. 7a,b) \\
\hline $\mathrm{f}_{\mathrm{a}}$ & $\mathrm{N}$ application efficiency & - & 1.0 \\
\hline $\mathrm{f}_{\mathrm{h}}$ & Ratio of harvest and total DM & - & 0.48 \\
\hline $\mathrm{f}_{\mathrm{u}}$ & $\mathrm{N}$ uptake efficiency & - & (Eq. 3) \\
\hline $\mathrm{E}_{\mathrm{p}}$ & Price ratio of fertilizer and harvested products & - & 4 \\
\hline $\mathrm{N}_{\mathrm{A}}$ & Available mineral $\mathrm{N}$ during period $\mathrm{T}_{0}$ to $\mathrm{T}_{\mathrm{M}}$ & $\mathrm{kg} \mathrm{ha}^{-1}$ & (Eq. 1) \\
\hline $\mathrm{N}_{\mathrm{F}}$ & Fertilizer rate & $\mathrm{kg} \mathrm{ha}^{-1}$ & $0-300$ \\
\hline $\mathrm{N}_{\min }$ & Mineral $\mathrm{N}$ content at $\mathrm{T}_{0}$ & $\mathrm{~kg} \mathrm{ha}^{-1}$ & 60 \\
\hline $\mathrm{N}_{\text {nat }}$ & $\begin{array}{l}N \text { not available at } T_{M} \text { due to transport limita- } \\
\text { tions }\end{array}$ & $\mathrm{kg} \mathrm{ha}^{-1}$ & 20 \\
\hline$N_{R}$ & $\mathrm{~N}$ residue at harvest & $\mathrm{kg} \mathrm{ha}^{-1}$ & (Eq. 15) \\
\hline $\mathrm{N}_{\mathrm{S}}$ & Part of $\mathrm{N}_{\mathrm{A}}$ derived from soil & $\mathrm{kg} \mathrm{ha}^{-1}$ & (Eq. 2) \\
\hline $\mathrm{N}_{\mathrm{U}}$ & $\mathrm{N}$ uptake by crop & $\mathrm{kg} \mathrm{ha}^{-1}$ & (Eq. $4 a, b)$ \\
\hline $\mathrm{N}_{\text {U.R }}$ & $\mathrm{N}$ uptake for maximum production & $\mathrm{kg} \mathrm{ha}^{-1}$ & (Eq. 5) \\
\hline RWR & Ratio of root and total plant dry weight & - & \\
\hline $\mathrm{R}_{\text {Netmin }}$ & Net mineralization rate & $\operatorname{kg}(\text { ha d })^{-1}$ & 1.0 \\
\hline $\mathbf{T}_{0}$ & Time of sampling $\mathrm{N}_{\min }$ & $\mathrm{d}$ & 0 \\
\hline $\mathrm{T}_{\mathrm{S}}$ & Time of start of linear growth & $\mathrm{d}$ & 7 \\
\hline $\mathrm{T}_{\mathrm{M}}$ & Time of maximum $\mathrm{N}$ content in crop & $\mathrm{d}$ & 52 \\
\hline$T_{H}$ & Time of harvest & $\mathrm{d}$ & 66 \\
\hline$T_{20-80}$ & Time from 20 to $80 \%$ of uptake & $\mathrm{d}$ & 45 \\
\hline$Y_{D}$ & Total dry matter production & $\mathrm{kg} \mathrm{ha}^{-1}$ & \\
\hline$Y_{D, M}$ & Maximum dry matter production & $\mathrm{kg} \mathrm{ha}^{-1}$ & 15000 \\
\hline$Y_{H}$ & Harvestable yield & $\mathrm{kg} \mathrm{ha}^{-1}$ & \\
\hline$Y_{H . M}$ & Maximum harvestable yield & $\mathrm{kg} \mathrm{ha}^{-1}$ & \\
\hline$Y_{S . M}$ & Maximum shoot dry matter production & $\mathrm{kg} \mathrm{ha}^{-1}$ & \\
\hline$\alpha$ & Relative value of $R_{N e t \min }$ in period $T_{M}$ to $T_{H}$ & - & 1.0 \\
\hline$\lambda$ & Luxury consumption fraction & - & 0.25 \\
\hline$\mu$ & Mean & & \\
\hline $\mathrm{Q}_{1}$ & $\begin{array}{l}\text { Spatial correlation of } \mathrm{N}_{\min } \text { and net mineraliza- } \\
\text { tion }\end{array}$ & - & 0.5 \\
\hline$\varrho_{2}$ & Spatial correlation of $N_{S}$ and $N_{F}$ & - & 0.0 \\
\hline$\sigma_{\mathrm{Nmin}}$ & Standard deviation $\mathrm{N}_{\min }$ & $\mathrm{kg} \mathrm{ha}^{-1}$ & 30 \\
\hline$\sigma_{\mathrm{Ns}_{\mathrm{s}}}$ & Standard deviation $\mathrm{N}_{\mathrm{S}}$ & $\mathrm{kg} \mathrm{ha}^{-1}$ & (Eq. 19) \\
\hline$(\sigma / \mu)_{(\text {Netmir }}$ & Coefficient of variation $R_{\text {Netmin }}$ & - & 0.33 \\
\hline$(\sigma / \mu)_{\mathrm{Nf}}$ & Coefficient of variation fertilization & - & 0.1 \\
\hline$(\sigma / \mu)_{\text {Nnat }}$ & Coefficient of variation $\mathrm{N}_{\text {nat }}$ & $\mathrm{kg} \mathrm{ha}^{-1}$ & 0.2 \\
\hline$\sigma_{\mathrm{Na}}$ & Standard deviation of total available $\mathrm{N}$ supply & $\mathrm{kg} \mathrm{ha}^{-1}$ & (Eq. 20) \\
\hline
\end{tabular}

Table 1. Parameters and standard values used for calculations. 
Mineralization in the period between $T_{M}$ and harvest time, $T_{H}$, contributes to the residue of mineral $\mathrm{N}$ at harvest, but not to 'available' $\mathrm{N}_{\mathrm{A}}$, according to our definition.

\section{Quadrant $I V$, relation between $N_{A}$ and $N_{U}$}

A certain amount of chemically 'available' nutrients in the root zone is not available to the root system at the required rate of uptake, because of transport limitations. The amount $\mathrm{N}_{\text {nat }}$ remaining in the soil at the moment that transport to the root system is just equal to crop demand, was specified by de Willigen \& van Noordwijk (1987). Figure 3 - calculated for $75 \%$ root-soil contact (Veen et al., 1992) - shows that $\mathrm{N}_{\text {nat }}$ is normally small for nitrate, unless low root length densities, $\mathrm{L}_{\mathrm{r} v}$, coincide with a relatively dry soil (low $\Theta$ ) and a high daily crop demand (high $\mathrm{A}$ ). $\mathrm{N}_{\text {nat }}$ was calculated here for regular root distributions. If non-regular root distributions occur and nitrogen is homogeneously distributed, $\mathrm{N}_{\text {nat }}$ will increase (de Willigen \& van Noordwijk, 1987); this effect can be interpreted as a reduction in effective root length density, normally by a factor in the range 0.6-0.9 (van Noordwijk, 1992). If non-regular root distributions coincide with heterogeneous $\mathrm{N}$ supply (synlocalization), $\mathrm{N}_{\text {nat }}$ might be smaller. For the standard case we assume a $\mathrm{N}_{\text {nat }}$ value of $20 \mathrm{~kg} \mathrm{ha}^{-1}$.

The value of $N_{\text {nat }}$ determines nitrogen uptake efficiency, $f_{u}$, for the conditions at which the uptake requirement for maximum crop growth $N_{U, R}$ can just be met:

$$
\mathrm{f}_{\mathrm{u}}(\mathrm{M})=\mathrm{N}_{\mathrm{U}, \mathrm{R}} /\left(\mathrm{N}_{\mathrm{U}, \mathrm{R}}+\mathrm{N}_{\text {nat }}\right)
$$

We assume that, when conditions allow, the maximum uptake rate exceeds $N_{U, R}$ by a fraction $\lambda$, representing 'luxury consumption' (see below).

At lower $\mathrm{N}$ supply, where the required uptake cannot be met, we assume that the uptake efficiency $f_{u}$ is equal to $f_{u}(M)$. Some justification for this choice is
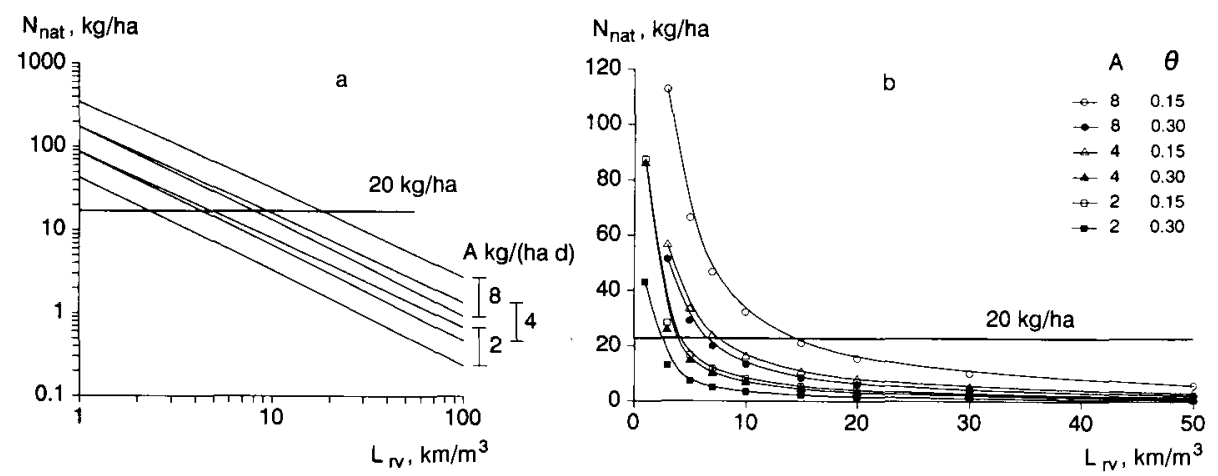

Fig. 3. Calculated values for $\mathrm{N}_{\text {nat }}$ as a function of root length density $\mathrm{L}_{\mathrm{rv}}$, adding effects of a $75 \%$ root-soil contact (Veen et al., 1992). Results are given on a logarithmic (a) and linear scale (b) for a range of values of daily crop demand $A$ and soil water content $\Theta(v / v)$. 
found in the reduction of $\mathrm{N}_{\text {nat }}$ by a period of zero-sink uptake, in which uptake rate is proportional to the average concentration in the soil (de Willigen \& van Noordwijk, 1987). Thus we obtain:

$$
\begin{aligned}
& N_{U}=f_{u}(M) N_{A}=\frac{N_{A} N_{U, R}}{\left(N_{U, R}+N_{n a t}\right)}, \text { for } N_{A}<\left(N_{U, R}+N_{\text {nat }}\right)(1+\lambda) \\
& N_{U}=N_{U, R}(1+\lambda), \text { for } N_{A}>\left(N_{U, R}+N_{n a t}\right)(1+\lambda)
\end{aligned}
$$

Quadrant I, relation between $N_{U}$ and $Y_{H}$

For this quadrant we first have to specify the required $\mathrm{N}$ uptake, $\mathrm{N}_{\mathrm{U}, \mathrm{R}}$, and secondly the reduction in crop yield if this required uptake rate cannot be met. If $\mathrm{C}_{\mathrm{m}}$ is the $\mathrm{N}$ concentration in the crop (averaged over the whole plant) when $\mathrm{N}$ is not limiting crop production, and $\mathrm{Y}_{\mathrm{D}, \mathrm{M}}$ is the maximum dry matter production as determined by factors other than $\mathrm{N}$ supply, the required uptake rate is:

$$
\mathrm{N}_{\mathrm{U}, \mathrm{R}}=\mathrm{C}_{\mathrm{m}} \mathrm{Y}_{\mathrm{D}, \mathrm{M}}
$$

Total crop dry matter production, $Y_{D . M}$, is partitioned over below- and aboveground parts. If we define the root weight ratio, RWR, as the ratio of belowground and total dry matter production, we obtain:

$$
\mathrm{Y}_{\mathrm{D}, \mathrm{M}}=(1-\mathrm{RWR})^{-1} \mathrm{Y}_{\mathrm{S}, \mathrm{M}}
$$

where $\mathrm{Y}_{\mathrm{S}, \mathrm{M}}$ is maximum shoot production. For most crops RWR will be less than 0.1 . For widely different crops a similar relationship between aboveground dry matter production and $\mathrm{N}$ uptake under non-limiting $\mathrm{N}$ supply exists. Average $\mathrm{N}$ concentration falls from about $5 \%$ in young plants to around $1.5 \%$ in older plants. De Willigen \& van Noordwijk (1987) showed that an adequate description for the present purpose is formed by:

$$
\begin{aligned}
& \mathrm{C}_{\mathrm{m}}=0.05, \text { for } \mathrm{Y}_{\mathrm{S}, \mathrm{M}}<2000 \\
& \mathrm{C}_{\mathrm{m}}=0.01+80 / \mathrm{Y}_{\mathrm{S}, \mathrm{M}}, \text { for } \mathrm{Y}_{\mathrm{S}, \mathrm{M}}>2000
\end{aligned}
$$

Within the relevant range, Equation 7 is close to the relation used by Greenwood et al. (1985). Much less reliable information is available on $\mathrm{N}$ contents of belowground tissues of field-grown crops. Here we assume that it is equal to that of aboveground parts.

Equation 7 also describes the relation between $\mathrm{N}$ uptake and dry matter production $Y_{D}$ during crop development, under non-limiting $N$ supply. An aboveground dry matter production of $2000 \mathrm{~kg}$ per ha roughly corresponds with a closed crop canopy and the transition from the exponential to the linear growth phase. 
When cumulative $\mathrm{N}$ uptake is plotted as a function of time, a sigmoid shape is evident (compare graph of van Itallie quoted by van Noordwijk et al., 1990). Between 20 and $80 \%$ of cumulative uptake, a linear approximation gives a good fit. The interval up to maximum $\mathrm{N}$ content of the crop, $\mathrm{T}_{\mathrm{M}}-\mathrm{T}_{0}$, can be derived from the duration of this linear uptake phase, $\mathrm{T}_{20-80}$, and from an initial period, $\mathrm{T}_{\mathrm{S}}-\mathrm{T}_{0}$ :

$$
\mathrm{T}_{\mathrm{M}}-\mathrm{T}_{0}=\mathrm{T}_{20-80} / 0.6+\mathrm{T}_{\mathrm{S}}-\mathrm{T}_{0}
$$

$\mathrm{T}_{0}=$ time of measurement of $\mathrm{N}_{\min }, \mathrm{T}_{20-80}=$ time interval between 20 and $80 \%$ of cumulative net uptake, $T_{S}=$ start of uptake period, extrapolated from linear approximation to cumulative uptake curve, and $T_{M}=$ time of maximum nutrient content, extrapolated from linear approximation to cumulative uptake curve.

Cumulative $\mathrm{N}$ uptake usually precedes cumulative dry matter production by 2 to 3 weeks. If the linear uptake rate is extrapolated to zero, a time lag of at least 1 week after crop emergence is seen for most crops. The value of $\left(T_{s}-T_{0}\right)$ then depends on the timing of the sampling for mineral soil $\mathrm{N}$ content. The physiological utilization efficiency, dry matter production per unit nutrient uptake, generally decreases when the maximum production level is reached. For many crops the relation between dry matter production and $\mathrm{N}$ uptake at harvest time can be described with an ascending branch of a quadratic equation through the origin:

$$
Y_{D}=\left\{\frac{2 N_{U}}{C_{m}}\right\}\left\{1-\frac{N_{U}}{2 N_{U, R}}\right\}, \text { for } N_{U}<N_{U, R}
$$

This description implies that $\mathrm{N}_{\mathrm{U}} / \mathrm{Y}_{\mathrm{D}}$ will approach $\mathrm{C}_{\mathrm{m}} / 2$ for low values of $\mathrm{N}_{\mathrm{U}}$ and thus that the minimum concentration at which plants can grow at all is half of $\mathrm{C}_{\mathrm{m}}$. Above the uptake requirement $\mathrm{N}_{\mathrm{U}, \mathrm{R}}$ a certain extra $\mathrm{N}$ uptake may occur, which is usually referred to as 'luxury consumption' (Equation 4). In the present model, luxury consumption helps to reduce residual $\mathrm{N}_{\min }$ at harvest. A tentative $25 \%$ increase over $\mathrm{N}_{\mathrm{U}, \mathrm{R}}$ is used as standard value $(\lambda=0.25)$. Finally, the harvested yield $\mathrm{Y}_{\mathrm{H}}$ must be obtained as a fraction, $\mathrm{f}_{\mathrm{h}}$, of the total dry matter production, $\mathrm{Y}_{\mathbf{D}}$ :

$$
\mathrm{Y}_{\mathrm{H}}=\mathrm{f}_{\mathrm{h}} \mathrm{Y}_{\mathrm{D}}
$$

The 'harvest index' $f_{h}$ is largely a cultivar characteristic independent of yield level, unless sudden interruptions of the growth cycle occurred, e.g. by drought. Here we assume $f_{h}$ to be constant.

Quadrant II, the relation between $N_{F}$ and $Y_{H}$

Quadrants III, IV and I together determine the nitrogen response curve of the crop in Quadrant II. Equations 1, 3, 4, 5, 9 and 10 can be combined to the yield function: 


$$
Y_{H}=\frac{f_{h}{ }^{2} f_{u}\left(N_{S}+f_{a} N_{F}\right)\left\{2 C_{m} Y_{D, M}-f_{u}\left(N_{S}+f_{a} N_{F}\right)\right\}}{C_{m}{ }^{2} Y_{H, M}}
$$

By taking $d Y_{H} / d_{F}$ equal to the price ratio $E_{p}$, price per unit fertilizer divided by price per unit harvested product, we can derive the 'maximum economic yield', $\mathrm{Y}_{\mathrm{MEY}}$, and the 'economic optimum' fertilizer rate, $\mathrm{N}_{\mathrm{MEY}}$. For fertilizer use at higher rates the costs of fertilizer will exceed the benefits.

$$
\begin{aligned}
& d Y_{H} / d N_{F}=E_{p} \\
& N_{M E Y}=\frac{C_{m} Y_{H, M}\left(2 f_{a} f_{u} f_{h}-E_{p} C_{m}\right)}{2\left(f_{a} f_{u} f_{h}\right)^{2}}-\frac{N_{s}}{f_{a}} \\
& Y_{M E Y}=Y_{H, M}\left\{1-\left(\frac{C_{m} E_{p}}{2 f_{a} f_{u} f_{h}}\right)^{2}\right\}
\end{aligned}
$$

Equation 13 has the form of most of the current $\mathrm{N}$ recommendations: a fixed amount of fertilizer $\mathrm{N}$ minus an estimate of the mineral $\mathrm{N}$ supply of the soil. Equation 14 shows that if $E_{p}$ approaches zero $Y_{M E Y}$ will approach $Y_{H, M}$. The yield level at the economic optimum fertilizer rate is apparently independent of the mineral $\mathrm{N}$ supply from the soil.

\section{Quadrant II, relation between $N_{F}$ and $N_{R}$}

All available $\mathrm{N}$ which was not taken up by the crop plus the amount mineralized in the period $T_{M}$ to $T_{H}$ (time of harvest) is supposed to be residual soil mineral $\mathrm{N}$ at harvest time, $\mathrm{N}_{\mathrm{R}}$.

$$
\begin{aligned}
& N_{R}=N_{A}-N_{U}+\alpha \int_{T_{M}}^{T_{H}} R_{N e t m i n} d t= \\
& \quad\left(1-f_{u}\right)\left(N_{S}+f_{a} N_{F}\right)+\alpha\left(T_{H}-T_{M}\right) R_{\text {Netmin }}
\end{aligned}
$$

The factor $\alpha$ indicates the ratio of the average value for $R_{\text {Netmin }}$ over the period $T_{M}$ to $T_{H}$ and that over the period $T_{0}$ to $T_{M}$. For the standard situation $\alpha$ is assumed to be 1.0; other values represent other degrees of synchrony between mineralization and crop demand. In the standard case we assume a period of 2 weeks before harvest without $\mathrm{N}$ uptake. For the residue of mineral $\mathrm{N}$ in the soil at harvest time at the maximum economic yield level, $\mathbf{N}_{\mathrm{R}, \mathrm{MEY}}$ we can derive from (13) and (15):

$$
N_{R, M E Y}=\left(1-f_{u}\right) \frac{C_{m} Y_{H, M}\left(2 f_{a} f_{u} f_{h}-E_{p} C_{m}\right)}{2 f_{a}\left(f_{u} f_{h}\right)^{2}}+\alpha\left(T_{H}-T_{M}\right) R_{\text {Netmin }}
$$


If an environmental standard, $\mathrm{N}_{\mathrm{R}}(\mathrm{E})$, is imposed on the residue of mineral $\mathrm{N}$ at harvest time, the maximum allowable fertilizer rate, $\mathrm{N}_{\mathrm{EAP}}(\mathrm{E})$, is derived from (15):

$$
N_{E A P}(E)=\frac{N_{R}(E)-\alpha\left(T_{H}-T_{M}\right) R_{\text {Netmin }}-\left(1-f_{u}\right) N_{S}}{\left(1-f_{u}\right) f_{a}}
$$

The difference $\mathrm{N}_{\text {EAP }}(E)-\mathrm{N}_{M E Y}$ can now be obtained from (13) and (17):

$$
N_{E A P}(E)-N_{M E Y}=\frac{N_{R}(E)-\alpha\left(T_{H}-T_{M}\right) R_{N e t m i n}}{\left(1-f_{u}\right) f_{a}}-\frac{C_{m} Y_{H, M}\left(2 f_{a} f_{u} f_{h}-E_{p} C_{m}\right)}{2\left(f_{a} f_{u} f_{h}\right)^{2}}
$$

Equation 18 shows that the difference between environmentally acceptable and economic optimum fertilizer application rates will be more positive, or less negative, for low $\mathrm{R}_{\mathrm{Netmin}}$, low $\alpha$, high $\mathrm{E}_{\mathrm{p}}$ and low $\mathrm{Y}_{\mathrm{H}, \mathrm{M}}$. The effect of the efficiency parameters $f_{a}, f_{u}$ and $f_{h}$ depends on values of other parameters.

\section{Model with variability}

For each of the three $\mathrm{N}$ sources in Quadrant $\mathrm{I}$, spatial variability should be taken into account. Measurements of variability in $\mathrm{N}_{\min }$ in the soil in spring suggest large differences in variability between fields. Measured frequency distributions of $\mathbf{N}_{\min }$ tend to be skewed, and sometimes a log-normal rather than a normal distribution is indicated. As discussed by White et al. (1987), in grazed pastures $\mathbf{N}_{\min }$ has an apparently log-normal, in the absence of grazing and urinating animals a normal distribution. In a normal distribution the standard deviation $\sigma_{n}$ of a composite sample, based on $\mathrm{n}$ subsamples, can be calculated from the standard deviation of a single sample, $\sigma_{1}$, as $\sigma_{\mathrm{n}}=\sigma_{1} / \sqrt{\mathrm{n}}$. If a strong spatial correlation exists between subsamples, or when the distribution is log-normal rather than normal, this equation is not valid. Figure 4 is based on two studies where a large number of individual subsamples were analysed for mineral $\mathrm{N}$, as well as composite samples with gradually increasing $n$ value. Measured values for $\sigma_{n}$ can be adequately predicted from $\sigma_{1}$ for these situations. In standard practice, $N_{\min }$ is analysed from composite samples based on ten individual samples; thus the standard deviation is reduced by $\sqrt{10}$. For the present model we assume a normal distribution of mineral $\mathrm{N}$ in the soil.

In Table 2 , values of the standard deviation of a single sample, $\sigma_{1}$, are compiled from studies where individual samples or a number of composite samples were analysed. In the latter case the equation $\sigma_{\mathrm{n}}=\sigma_{1} / \sqrt{\mathrm{n}}$ was used. For the 21 entries referring to the depth 0 to 0.6 up to 0 to $1.2 \mathrm{~m}$, the median value of $\sigma_{1}$ is $37 \mathrm{~kg}$ $\mathrm{ha}^{-1}$, the maximum is eight times higher. The median value for the coefficient of variation $\left(\sigma_{1} / \mu\right)$ is $38 \%$. We may expect that variability at the level of a single plant (the unit soil area) is less than $\sigma_{1}$; the extent to which it is reduced is not known, however, as on this scale a strong spatial correlation may be expected. For 


\section{Calculated variation coeff.}

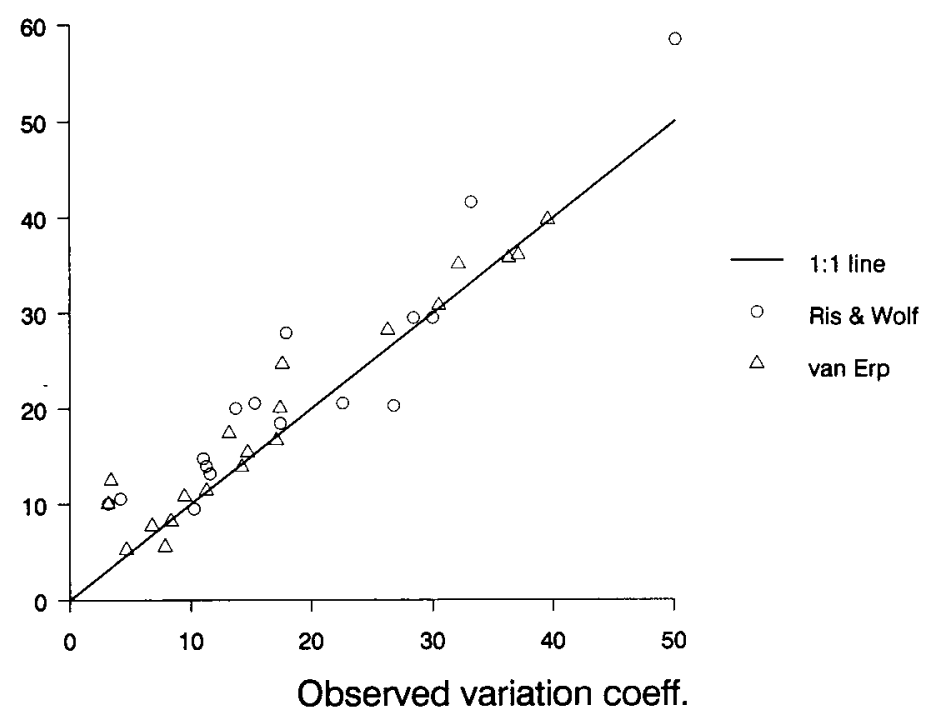

Fig. 4. Comparison of observed coefficients of variation (standard deviations expressed as percentage of the field average) of composite samples and calculated values, based on the standard deviation of individual subsamples and on the assumption of normally-distributed subsample values. Data of Ris \& Wolf (1979) are based on several combinations of individual soil samples taken at four locations, the data of P.J. van Erp (pers. comm.) on a single field.

the standard case we assume the standard deviation in $\mathrm{N}_{\min }$ to be $30 \mathrm{~kg} \mathrm{ha}^{-1}$.

The second contributor to soil nitrogen is the net mineralization during the growing season. Mineralization mainly originates from recent inputs of crop residues, green manures, slurry or manure. Spatial variability in net mineralization will depend on variability in (a) the amount of mineralizable material, (b) mineralization rate and (c) nitrogen losses. The first component will depend on the application technique for organic inputs. The second component will depend on variability in such factors as temperature and (fluctuations in) soil water content, which modify mineralization rates. Possible $\mathrm{N}$ losses during the season are subtracted from mineralization to derive a net mineralization rate. A proper analysis of these three components of spatial variability and in their overall effect has, to our knowledge, not yet been performed. We assume for the standard case that the integral over time of $\mathrm{R}_{\mathrm{Netmin}}$ has a coefficient of variation of $33 \%$ and a standard deviation of $17 \mathrm{~kg} \mathrm{ha}^{-1}$.

For the model we also have to specify the correlation coefficient $\varrho_{1}$ between spatial patterns in $\mathrm{N}_{\min }$ in spring and subsequent mineralization rate. For the standard case we assume that a partial correlation exists, $\varrho_{1}=0.5$. This results in a total variability for $\mathrm{N}$ derived from the soil, $\sigma_{\mathrm{Ns}}{ }^{2}$ : 
Table 2. Values of the standard deviation in $\mathrm{N}_{\min }$ in spring for individual soil samples; in a number of cases results were calculated from data from composite samples, based on $\mathbf{n}$ subsamples.

\begin{tabular}{|c|c|c|c|c|c|}
\hline \multirow{2}{*}{$\begin{array}{l}\text { Soil layer } \\
(\mathrm{m})\end{array}$} & \multicolumn{3}{|c|}{ Mineral N in soil } & \multirow{2}{*}{$\begin{array}{l}\text { Number of } \\
\text { subsamples } n\end{array}$} & \multirow[t]{2}{*}{ Reference } \\
\hline & $\begin{array}{l}\text { mean } \\
\left(\mathrm{kg} \mathrm{ha}^{-1}\right)\end{array}$ & $\begin{array}{l}\mathrm{SD} \\
\left(\mathrm{kg} \mathrm{ha}^{-1}\right)\end{array}$ & $\begin{array}{l}\sigma_{1} / \mu \\
(\%)\end{array}$ & & \\
\hline $0-0.15$ & 23 & 9 & 40 & 1 & Cameron et al. (1971) \\
\hline $0-0.15$ & 20 & 14 & 72 & 1 & id. \\
\hline $0-0.15$ & 15 & 7 & 47 & 1 & id. \\
\hline $0-0.15$ & - & - & $57^{\mathrm{a}}$ & 1 & Hunt et al. (1979) \\
\hline $0-0.15$ & 46 & 16 & 35 & 1 & Briggs (1974) \\
\hline $0-0.3$ & 21 & 10 & 49 & 1 & Cameron et al. (1971) \\
\hline $0-0.3$ & 33 & 11 & 34 & 1 & \\
\hline $0-0.3$ & 13 & 3 & 23 & 3 & Dahiya et al. (1984) \\
\hline $0.3-0.6$ & 18 & 5 & 29 & 3 & Dahiya et al. (1984) \\
\hline $0.6-0.9$ & 29 & 8 & 29 & 3 & Dahiya et al. (1984) \\
\hline $0-0.6$ & 24 & 13 & 53 & 1 & Cameron et al. (1971) \\
\hline $0-0.6$ & 56 & 19 & 35 & 1 & \\
\hline $0-0.6$ & 47 & 27 & 57 & 1 & P. Finke (pers. comm.) \\
\hline $0-0.6$ & 316 & 102 & 32 & 1 & id. \\
\hline $0-0.6$ & 22 & 7 & 33 & 1 & $\begin{array}{l}\text { P.J. van Erp (pers. } \\
\text { comm.) }\end{array}$ \\
\hline $0-0.6$ & 25 & 10 & 41 & 1 & id. \\
\hline $0-0.6$ & 101 & 31 & 30 & 1 & id. \\
\hline $0-0.6$ & 36 & 17 & 49 & 1 & id. \\
\hline $0-0.9$ & - & $5^{\mathrm{b}}$ & - & 1 & Richter et al. (1984) \\
\hline $0-1.0$ & $51^{\mathrm{c}}$ & $16^{\mathrm{c}}$ & 31 & 3 & $\begin{array}{l}\text { van Meirverne \& Hof- } \\
\text { man (1989) }\end{array}$ \\
\hline $0-1.0$ & 57 & 47 & 83 & 10 & Kolenbrander (1968) \\
\hline $0-1.0$ & 76 & 38 & 50 & 10 & id. \\
\hline $0-1.0$ & 98 & 54 & 55 & 10 & id. \\
\hline $0-1.0$ & 123 & 20 & 16 & 1 & $\begin{array}{l}\text { Knittel \& Fischbeck } \\
\text { (1979) }\end{array}$ \\
\hline $0-1.0$ & 127 & 53 & 42 & 1 & Ris \& Wolf (1979) \\
\hline $0-1.0$ & 99 & 36 & 37 & 1 & id. \\
\hline $0-1.0$ & 94 & 37 & 40 & 1 & id. \\
\hline $0-1.0$ & 376 & 311 & 83 & 1 & id. \\
\hline $0-1.2$ & 160 & 40 & 25 & 1 & Bole \& Pittman (1976) \\
\hline $0-1.2$ & 133 & 36 & 27 & 1 & \\
\hline $0-1.2$ & 183 & 46 & 25 & 1 & id. \\
\hline
\end{tabular}

${ }^{\mathrm{a}}$ Median

${ }^{b}$ Irrespective of $\mathrm{N}$ level

c When asuming a bulk density of $1.4 \mathrm{Mg} \mathrm{m}^{-3}$

$$
\sigma_{\mathrm{Ns}}^{2}=\sigma_{\mathrm{Nmin}}^{2}+\sigma_{\int \mathrm{Netmin}}{ }^{2}+2 \varrho_{1} \sigma_{\mathrm{Nmin}} \sigma_{\int \mathrm{Netmin}}
$$

The third contributor of mineral $\mathrm{N}$ is recently applied $\mathrm{N}$ fertilizer. Spatial varia- 
bility in the amounts applied per unit soil area depends on the equipment and type of fertilizer used. A coefficient of variation $(\sigma / \mu)_{\mathrm{Nf}}$ of $10 \%$ is used here which reflects a technically feasible target (Dilz \& van Brakel, 1985).

Total variability in available nitrogen supply, $\sigma_{\mathrm{Na}}{ }^{2}$ is:

$$
\sigma_{N a}^{2}=\sigma_{N s}^{2}+N_{f}^{2}(\sigma / \mu)_{N f}^{2}+2 \varrho_{2} \sigma_{N s} N_{f}(\sigma / \mu)_{N f}
$$

In the standard situation we assume that $\varrho_{2}=0$, i.e. no correlation exists between spatial patterns of $\mathrm{N}$ fertilization and of soil mineral $\mathrm{N}$ supply, either as initial $\mathrm{N}_{\min }$ or as subsequent mineralization.

Spatial variability also exists in parameters determining the shape of the relation in Quadrant IV. Several of the factors on which $N_{\text {nat }}$ depends may show considerable variability between individual plants, especially root length density and soil water content. For root length density in standard auger samples of $38510^{-6}$ $\mathrm{m}^{3}$ a coefficient of variation of $30-50 \%$ can be expected for relatively homogeneous soil conditions (van Noordwijk et al., 1985). Expressed per individual plant or 'unit soil area' the variation will be less. For the standard situation a coefficient of variation for $(\sigma / \mu)_{\text {Nnat }}$ of $20 \%$ is assumed.

To study effects of variability, calculations were based on the complete frequency distribution, split into $1 \%$ fractions. The sum for these fractions is presented as total yield for a whole field and expressed per ha. If variability in two quadrants is taken into account, calculations were based on $100 \times 100$ fractions, each representing a $10^{-4}$ part of the population on the field. We chose this approach rather than Monte-Carlo simulations, as a cropped field is a sufficiently large population of individual plants to assume that a normal distribution will be fully realized.

Two versions of the model with variability, one in GW-Basic for use on a PC and one in GENSTAT-5 for a microcomputer, are available from the authors, on request.

\section{Results}

Values for $\mathrm{N}_{\mathrm{MEY}}$ (Equation 13), $\mathrm{N}_{\text {EAP }}$ (Equation 17) and relative yield loss (compared to $\mathrm{Y}_{\max }$ ) for the standard parameter set without spatial variability are given as first horizontal entry in Table 3. A positive difference exists in this situation between $\mathrm{N}_{\mathrm{EAP}}$ and $\mathrm{N}_{\mathrm{MEY}}$ even for the strictest environmental standard. $\mathrm{Y}_{\mathrm{MEY}}$ in this case is $99.7 \%$ of $\mathrm{Y}_{\max }$ and applying the economic optimum fertilizer rate increases the $\mathrm{N}$ residue at harvest time by only $8 \mathrm{~kg} \mathrm{ha}^{-1}$ compared to a non-fertilized control. For $\mathrm{N}_{\mathrm{F}}$ rates above $\mathrm{N}_{\mathrm{MEX}}$ the $\mathrm{N}$ content of the crop increases, as determined by the luxury consumption parameter $\lambda$, and only after the crop uptake capacity has been fully utilized $N_{R}$ starts to increase linearly with increasing $\mathrm{N}_{\mathrm{F}}$ (Figure 5).

Adding effects of variability, using 'standard' parameter values (Table 1), led to an increase of $\mathrm{N}_{\text {EAP }}$ of $23 \mathrm{~kg}$ per ha and a decrease in $\mathrm{N}_{\text {EAP }}(\mathrm{E})$ of 16,35 and 12 $\mathrm{kg} \mathrm{ha}^{-1}$ for environmental standards of 34,45 and $70 \mathrm{~kg} \mathrm{ha}^{-1}$, respectively. The 
Table 3. Results of simulations with a standard set of parameters (Table 1) with different levels of variability: none, standard and double. Five variability factors were doubled one by one and all together. $\mathrm{N}$ fertilizer rate and relative yield loss are given for the economic optimum, $\mathrm{N}_{\mathrm{MEY}}$, and for situations where the $\mathrm{N}$ residue is 34,45 or $70 \mathrm{~kg} \mathrm{ha}^{-1}, \mathrm{~N}_{\text {EAP }}(34), \mathrm{N}_{\text {EAP }}$ (45) and $\mathrm{N}_{\text {EAP }}$ (70), respectively.

\begin{tabular}{|c|c|c|c|c|c|c|c|c|c|c|}
\hline & \multicolumn{2}{|c|}{$\begin{array}{l}\mathrm{N} \text { residue } N_{R} \\
\left(\mathrm{~kg} \mathrm{ha}^{-1}\right)\end{array}$} & \multicolumn{4}{|c|}{$\mathrm{N}$ fertilizer rate $\left(\mathrm{kg} \mathrm{ha}^{-1}\right)$} & \multicolumn{4}{|c|}{ Relative yield loss (\%) } \\
\hline & \multirow[t]{2}{*}{$0-\mathrm{N}$} & \multirow[t]{2}{*}{$\mathrm{N}_{\mathrm{MEY}}$} & \multirow[t]{2}{*}{$\mathrm{N}_{\mathrm{MEY}}$} & \multicolumn{3}{|c|}{$\mathrm{N}_{\mathrm{EAP}}$} & \multirow[t]{2}{*}{$\mathrm{N}_{\mathrm{MEY}}$} & \multicolumn{3}{|c|}{$\mathrm{N}_{\mathrm{EAP}}$} \\
\hline & & & & 34 & 45 & 70 & & 34 & 45 & 70 \\
\hline No variability & 25.4 & 33.0 & 95 & 108 & 176 & 201 & 0.3 & 0.0 & 0.0 & 0.0 \\
\hline Standard var. & 25.3 & 38.7 & 118 & 92 & 141 & 189 & 1.5 & 3.3 & 0.7 & 0.1 \\
\hline \multicolumn{11}{|l|}{ Doubled var.: } \\
\hline$(\sigma / \mu)_{\text {Nnat }}$ & 25.2 & 38.7 & 118 & 93 & 140 & 189 & 1.5 & 3.3 & 0.7 & 0.1 \\
\hline$(\sigma / \mu)_{\mathrm{Nf}}$ & 25.3 & 39.5 & 118 & 91 & 136 & 185 & 1.8 & 3.7 & 1.1 & 0.3 \\
\hline$\varrho_{1}$ & 25.3 & 42.3 & 125 & 86 & 134 & 185 & 1.7 & 4.8 & 1.3 & 0.2 \\
\hline$\sigma_{f \mathrm{Netmin}}$ & 25.7 & 53.6 & 142 & 71 & 119 & 176 & 2.1 & 9.3 & 3.6 & 0.9 \\
\hline$\sigma_{\mathrm{Ns}}$ & 25.7 & 56.0 & 146 & 68 & 116 & 174 & 2.2 & 10.3 & 4.2 & 1.1 \\
\hline All & 28.6 & 92.9 & 189 & 33 & 80 & 145 & 3.5 & 26.9 & 15.6 & 6.6 \\
\hline \multicolumn{11}{|l|}{ Other cases: } \\
\hline$(\sigma / \mu) \mathrm{N}_{\text {nat }}=0.8$ & 25.6 & 38.8 & 119 & 94 & 139 & 188 & 1.5 & 3.2 & 0.8 & 0.1 \\
\hline \multirow[t]{2}{*}{$(\sigma / \mu)_{\mathrm{Nf}}$} & 26.1 & 38.4 & 118 & 93 & 142 & 191 & 1.4 & 3.2 & 0.6 & 0.1 \\
\hline & 25.3 & 41.6 & 114 & 85 & 123 & 170 & 3.2 & 5.1 & 2.8 & 1.5 \\
\hline
\end{tabular}

difference between $\mathrm{N}_{\text {EAP }}$ and $\mathrm{N}_{\mathrm{MEY}}$ thus decreased and became negative for the $34 \mathrm{~kg} \mathrm{ha}^{-1}$ standard. $\mathrm{N}_{\mathrm{R}}$ now rose rapidly with increasing $\mathrm{N}_{\mathrm{F}}$ before crop uptake capacity had been fully utilized.

Table 3 also gives results for situations in which the various components of variability are doubled, either one by one or all together. Model results were insensitive to the values for $(\sigma / \mu) \mathrm{N}_{\text {nat }}$ and $(\sigma / \mu)_{\mathrm{Nf}}$. Increased values of $\sigma_{\mathrm{Ns}}$ and $\sigma_{\int \mathrm{Netmin}}$, however, had a considerable effect on model results and led to a further increase of $\mathrm{N}_{\text {MEY }}$ and a decrease of $\mathrm{N}_{\text {EAP }}(E)$. When all variability components were doubled, $\mathrm{N}_{\text {MEY }}$ reached double the value without variability and even the difference between $N_{\text {EAP }}(70)$ and $N_{\text {MEY }}$ became negative. These results were obtained with the same average values for all parameters normally determined in field experiments or when giving fertilizer recommendations.

Table 3 shows that $(\sigma / \mu)_{\text {Nnat }}$ is relatively unimportant; even when a value of $80 \%$ was used, small effects were obtained. The small effect of doubling $(\sigma / \mu)_{\mathrm{Nf}}$ was checked by considering two further values, 5 and $40 \%$, respectively. Table 3 shows that increased variability of fertilizer application had little effect on the 


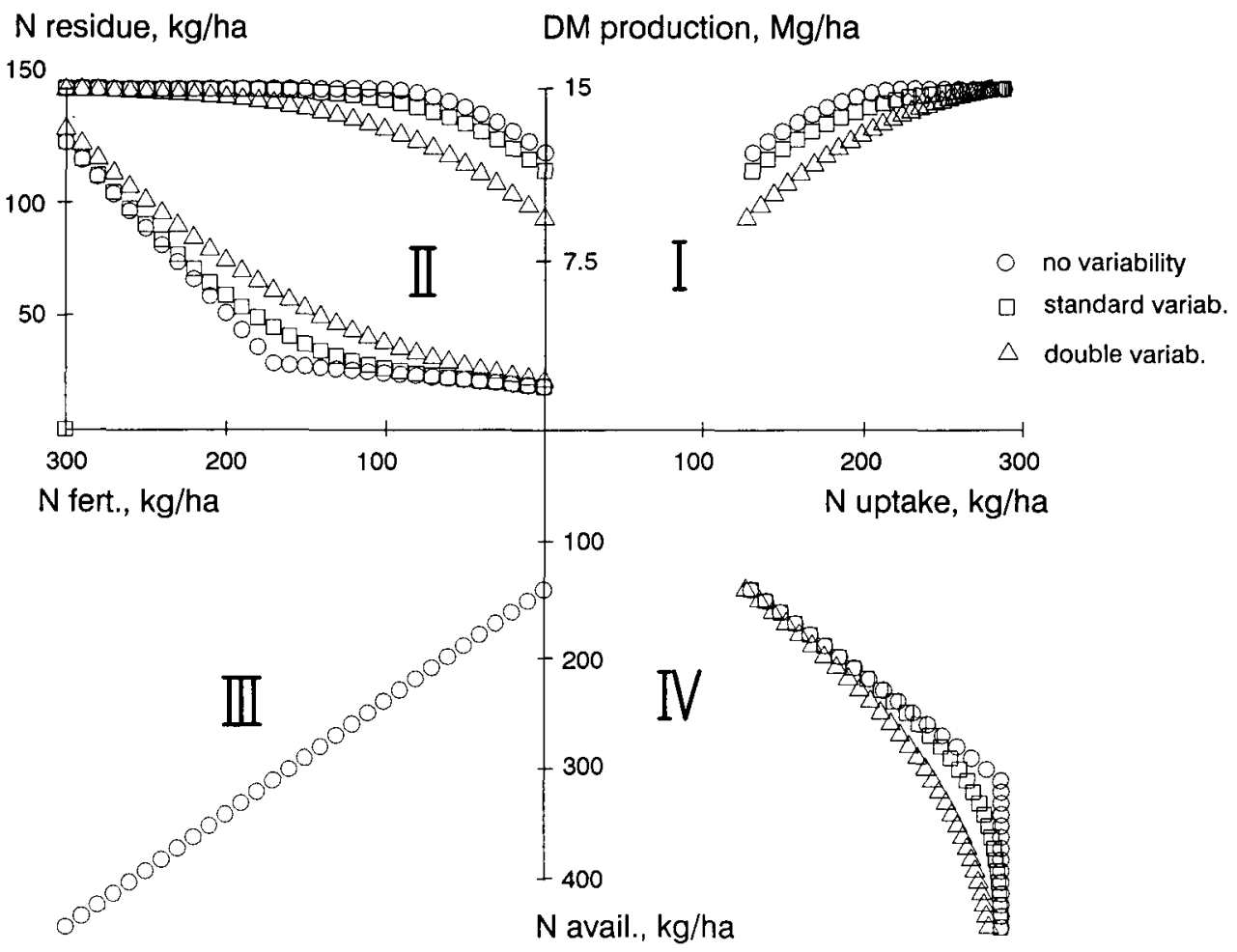

Fig. 5. Four-quadrant representation of the fertilizer response for the standard data set, with no, standard and doubled variability.

residual $\mathrm{N}$ at harvest, provided that for each case a real 'economic optimum' fertilizer rate was used. The main effect of an increased $(\sigma / \mu)_{\mathrm{Nf}}$ was a reduction of the $\mathrm{Y}_{\mathrm{MEY}}$ by a few percent.

Table 4 gives model calculations for some additional cases where other model parameters were modified around the standard values. Increasing the value of $\mathrm{N}_{\text {nat }}$ led to an increase of $\mathrm{N}_{\mathrm{MEY}}$, by about $70 \%$ of the increase of $\mathrm{N}_{\text {nat }}$, but had a much more pronounced effect on $\mathrm{N}_{\mathrm{EAP}}$ and hence on the difference between $\mathrm{N}_{\text {EAP }}$ and $\mathrm{N}_{\mathrm{MEY}}$. According to de Willigen \& van Noordwijk (1987) we expected that changes in $Y_{\max }$ based on the same growing period, are accompanied by a proportional change in $\mathrm{N}_{\text {nat }}$. Table 4 shows the effects of a simultaneous change of both parameters. Increasing values for $\mathrm{Y}_{\max }$ and $\mathrm{N}_{\text {nat }}$ led to a linear increase in $\mathrm{N}_{M E Y}$ values. The $\mathrm{N}_{\text {EAP }}$ values were influenced in a strongly non-linear way. Around the standard parameter set, increasing $Y_{\text {max }}$ and $N_{\text {nat }}$ made the difference between $\mathrm{N}_{\mathrm{EAP}}(34)$ and $\mathrm{N}_{\mathrm{MEY}}$ more negative, the difference with $\mathrm{N}_{\mathrm{EAP}}(70)$ more positive and had a variable effect on the difference with $\mathrm{N}_{\text {EAP }}(45)$.

As may be expected, results for the difference between $N_{\text {EAP }}$ and $N_{M E Y}$ were very sensitive to the value of the luxury consumption parameter $\lambda$ and the syn- 
Table 4. Effects of modifying parameter values for $Y_{\max }, \alpha, \varrho_{1}, \varrho_{2}$.

\begin{tabular}{|c|c|c|c|c|c|c|c|c|c|c|}
\hline & \multicolumn{2}{|c|}{$\begin{array}{l}\mathrm{N} \text { residue } N_{R} \\
\left(\mathrm{~kg} \mathrm{ha}^{-1}\right)\end{array}$} & \multicolumn{4}{|c|}{$\mathrm{N}$ fertilizer rate $\left(\mathrm{kg} \mathrm{ha}^{-1}\right)$} & \multicolumn{4}{|c|}{ Relative yield loss (\%) } \\
\hline & \multirow[t]{2}{*}{$0-\mathrm{N}$} & \multirow[t]{2}{*}{$\mathrm{N}_{\mathrm{MEY}}$} & \multirow[t]{2}{*}{$\mathrm{N}_{\mathrm{MEY}}$} & \multicolumn{3}{|c|}{$\mathrm{N}_{\text {EAP }}$} & \multirow[t]{2}{*}{$\mathrm{N}_{\mathrm{MEY}}$} & \multicolumn{3}{|l|}{$\mathrm{N}_{\text {EAP }}$} \\
\hline & & & & 34 & 45 & 70 & & 34 & 45 & 70 \\
\hline$Y_{\max }=7500$ & 31.4 & 42.1 & 44 & 14 & 52 & 97 & 2.9 & 7.3 & 2.2 & 0.3 \\
\hline$=15000^{*}$ & 25.3 & 38.7 & 118 & 92 & 141 & 189 & 1.5 & 3.3 & 0.7 & 0.1 \\
\hline$=22500$ & 22.7 & 36.2 & 190 & 171 & 229 & 281 & 1.1 & 1.9 & 0.3 & 0.04 \\
\hline $\mathrm{N}_{\text {nat }}=10$ & 20.3 & 29.4 & 111 & 129 & 155 & 194 & 1.5 & 0.8 & 0.3 & 0.1 \\
\hline$=20^{*}$ & 25.3 & 38.7 & 118 & 92 & 141 & 189 & 1.5 & 3.3 & 0.7 & 0.1 \\
\hline$=40$ & 34.9 & 57.0 & 133 & - & 68 & 171 & 1.6 & 100 & 8.3 & 0.4 \\
\hline \multicolumn{11}{|l|}{$\mathrm{Y}_{\max }$ and $\mathrm{N}_{\mathrm{nat}}$} \\
\hline Standard $\times 0.5$ & 24.8 & 34.0 & 38 & 38 & 64 & 101 & 3.8 & 3.7 & 1.1 & 0.2 \\
\hline Standard & 25.3 & 38.7 & 118 & 92 & 141 & 189 & 1.5 & 3.3 & 0.7 & 0.1 \\
\hline Standard $\times 1.5$ & 26.7 & 45.9 & 197 & 82 & 192 & 272 & 1.1 & 13.3 & 1.3 & 0.1 \\
\hline Standard $\times 2$ & 27.5 & 54.5 & 277 & 69 & 185 & 272 & 1.0 & 16.3 & 6.6 & 0.1 \\
\hline$\lambda=0.125$ & 25.3 & 45.6 & 118 & 77 & 117 & 162 & 1.5 & 4.9 & 1.6 & 0.3 \\
\hline$=0.25^{*}$ & 25.3 & 38.7 & 118 & 92 & 141 & 189 & 1.5 & 3.3 & 0.7 & 0.1 \\
\hline$=0.375$ & 25.3 & 35.9 & 118 & 102 & 163 & 216 & 1.5 & 2.5 & 0.3 & 0.03 \\
\hline$=0.5$ & 25.3 & 35.0 & 118 & 107 & 185 & 243 & 1.5 & 2.1 & 0.1 & 0.004 \\
\hline$\alpha=0.25$ & 14.8 & 28.2 & 118 & 139 & 165 & 204 & 1.5 & 0.7 & 0.3 & 0.1 \\
\hline$=0.5$ & 18.3 & 31.7 & 118 & 128 & 158 & 199 & 1.5 & 1.1 & 0.4 & 0.1 \\
\hline$=1.0^{*}$ & 25.3 & 38.7 & 118 & 92 & 141 & 189 & 1.5 & 3.3 & 0.7 & 0.1 \\
\hline$=1.5$ & 32.3 & 45.7 & 118 & 21 & 115 & 178 & 1.5 & 16.1 & 1.7 & 0.2 \\
\hline$\varrho_{1}=-0.5$ & 25.3 & 33.7 & 103 & 106 & 157 & 197 & 1.0 & 0.9 & 0.04 & 0.001 \\
\hline$=0$ & 25.3 & 35.6 & 111 & 99 & 148 & 193 & 1.3 & 1.9 & 0.3 & 0.03 \\
\hline$=0.5^{*}$ & 25.3 & 38.7 & 118 & 92 & 141 & 189 & 1.5 & 3.3 & 0.7 & 0.1 \\
\hline$=1.0$ & 25.3 & 42.3 & 125 & 86 & 134 & 185 & 1.7 & 4.8 & 1.3 & 0.2 \\
\hline $\mathrm{Q}_{2}=-1$ & 25.3 & 35.5 & 114 & 101 & 156 & 199 & 1.0 & 1.7 & 0.1 & $<0.001$ \\
\hline$=-0.5$ & 25.3 & 37.0 & 116 & 96 & 147 & 194 & 1.2 & 2.5 & 0.3 & 0.02 \\
\hline$=0^{*}$ & 25.3 & 38.7 & 118 & 92 & 141 & 189 & 1.5 & 3.3 & 0.7 & 0.1 \\
\hline$=0.5$ & 25.3 & 40.5 & 121 & 89 & 135 & 185 & 1.8 & 4.1 & 1.2 & 0.3 \\
\hline
\end{tabular}

* Standard value

- Standard cannot be met

chrony parameter $\alpha$. Both parameter values had no effect on $\mathrm{N}_{\mathrm{MEY}}$. Changes in the value for the correlation coefficients $\varrho_{1}$ and $\varrho_{2}$ had a considerable effect on the difference between $\mathrm{N}_{\mathrm{EAP}}$ and $\mathrm{N}_{\mathrm{MEY}}$. Positive values for $\varrho_{2}$ might occur, e.g. if an inhomogeneous distribution pattern for fertilizer application is repeated year by year. Negative values for $\mathrm{Q}_{2}$ could be achieved if fertilizer rates are adjusted to estimates of local $\mathrm{N}$ supply by the soil. At the standard parameter set, the considerable effort to obtain negative values for $\mathrm{g}_{2}$ would lead to only a slight 
Table 5. Comparison of normal and log-normal distribution of $\mathrm{N}_{\min }$ and $\mathrm{R}_{\mathrm{Netmin}}$; standard parameter set, except for $\varrho_{1}=0$ and $(\sigma / \mu) N_{\text {nat }}=0$.

\begin{tabular}{|c|c|c|c|c|c|c|c|c|c|c|}
\hline \multirow[t]{3}{*}{$\begin{array}{l}\mathbf{N}_{\min } \text { distribution and } \\
\mathbf{R}_{\text {Netmin }} \text { value }\end{array}$} & \multicolumn{2}{|c|}{$\begin{array}{l}\mathrm{N} \text { residue } \mathrm{N}_{\mathrm{R}} \\
\left(\mathrm{kg} \mathrm{ha}^{-1}\right)\end{array}$} & \multicolumn{4}{|c|}{$\mathrm{N}$ fertilizer rate $\left(\mathrm{kg} \mathrm{ha}^{-1}\right)$} & \multicolumn{4}{|c|}{ Relative yield loss $(\%)$} \\
\hline & \multirow[t]{2}{*}{$0-\mathrm{N}$} & \multirow[t]{2}{*}{$\mathrm{N}_{\mathrm{MEY}}$} & \multirow[t]{2}{*}{$\mathrm{N}_{\mathrm{MEY}}$} & \multicolumn{3}{|c|}{$N_{\text {EAP }}$} & \multirow[t]{2}{*}{$\mathrm{N}_{\mathrm{MEY}}$} & \multicolumn{3}{|c|}{$\mathrm{N}_{\text {EAP }}$} \\
\hline & & & & 34 & 45 & 70 & & 34 & 45 & 70 \\
\hline Normal, standard & 25.4 & 37.4 & 113 & 97 & 144 & 191 & 1.4 & 2.7 & 0.5 & 0.001 \\
\hline $\begin{array}{l}\text { Log-normal, } \\
\text { standard }\end{array}$ & 25.4 & 37. & 11 & 90 & 142 & 19 & 1. & 2.6 & 0.003 & $<0.001$ \\
\hline Normal, double & 25.8 & 62.8 & 153 & 62 & 108 & 167 & 2.6 & 12.6 & 6.0 & 2.0 \\
\hline Log-normal, double & 28.4 & 56.6 & 139 & 41 & 99 & 172 & 1.4 & 14.9 & 4.6 & 0.004 \\
\hline
\end{tabular}

reduction in $\mathrm{N}_{\mathrm{MEY}}$ and a yield increase of at most $1.6 \%$ if the strictest environmental standards are applied.

Table 5 shows results of a comparison of a normal and a log-normal distribution of mineral $\mathrm{N}$ in spring for the standard parameter set, but with spatial correlation coefficient $\varrho_{1}=0$ and no variability in $\mathrm{N}_{\text {nat. }}$. The form of the log-normal distribution depends on the value of the (untransformed) standard deviation. For the standard value of $\sigma_{\mathrm{Ns}}$, model results were only slightly different for a log-normal distribution. When $\sigma_{\mathrm{Ns}}$ was doubled the difference between the two types of distribution was still small, especially for the difference between $N_{E A P}$ and $N_{M E Y}$.

\section{Discussion}

In general, validity of model conclusions depends on the adequacy of underlying assumptions, on the sensitivity of the model to slight deviations from the assumptions, and on the use of correct parameter values. Results of the present model about the importance of spatial variability were not essentially modified when a log-normal rather than a normal distribution was incorporated. The most critical assumptions are probably those made for Quadrant I. The shift of the yield response curve to the higher and of the residue curve to lower fertilizer rates when variability is taken into account, will probably occur for any realistic set of assumptions. The parameter values used reflect a rather abstract standard crop and model refinements to make it crop-specific are obviously required. For certain crops and fertilization practices the $\mathrm{N}$ supply required to obtain maximum growth rates in the crop establishment phase, may exceed the supply needed to avoid $\mathrm{N}$ shortages at crop maturity. Several of the parameters to which the model is most sensitive $\left(\lambda, \alpha, \sigma_{f \text { Netmin }}, \varrho_{1}\right)$ have not yet been sufficiently measured under practical conditions. Still, if we give emphasis to the effects of modifying parameter values, the model allows a number of general conclusions and suggests directions for further research.

Of the three factors, mentioned in the introduction, leading to $\mathrm{N}$ residues at 
harvest, transport limitations around the root system of a single plant appeared to be relatively unimportant as long as $N_{\text {nat }}$ remains less than about $20 \mathrm{~kg} \mathrm{ha}$. Mineralization after the time of maximum crop nutrient content and spatial variability in mineralization are dominant factors.

Model results showed that, given the standard parameter set, spatial variability in mineral $\mathrm{N}$ supply of the soil has a pronounced effect on the difference between $\mathrm{N}_{\text {EAP }}$ and $\mathrm{N}_{\text {MEY. }}$.

Current fertilizer recommendation schemes are based on models of the type $\mathrm{N}_{\text {MEY }}=\mathrm{a}-\mathrm{b} \mathrm{N}_{\min }$ fitted to large sets of field experiments (Neeteson, 1990). Equation 14, derived for a situation without variability, is in agreement with such fits and suggests in which way the value for a depends on the target crop yield. Model results including variability suggest that equations of the type $\mathrm{N}_{M E Y}=a-b$ $\mathrm{N}_{\text {min }}+\mathrm{f}\left(\sigma_{\mathrm{Ns}}\right)$ would improve fertilizer recommendations, provided that fieldspecific estimates of $\sigma_{\mathrm{Ns}}$ can be obtained. Calculations presented here suggest that $f\left(\sigma_{N s}\right)$ should be a non-linear function. The considerable effects on the economic optimum $\mathrm{N}$ fertilizer rate, of parameters influencing $\sigma_{\mathrm{Ns}}$, at constant average values for all parameters normally measured, shows that the major part of empirical quantitative evidence on soil-plant relationships is biased. Since the start of soil fertility experiments, sites for field experiments were chosen on the basis of a 'good homogeneity' or 'low variability'. This choice was considered to be necessary to improve the discriminative power of the experiment in a statistical sense. This choice, however, not only decreased the uncertainty of the results, but also introduced a considerable systematic error (bias). Results obtained were good, but not representative for agricultural soils. The effect of changing the value for $\sigma_{\mathrm{Ns}}$ in this model shows that fertilizer recommendations might have been formulated differently if experiments had been done at truly representative values of $\sigma_{\mathrm{Ns}}$. For heterogeneous soils the standard experimental technique leads to unreliable estimates of the economic optimum rate. Often confidence intervals for 'optimum' $\mathrm{N}$ fertilizer rates exceed the range tested; they may even span values of -2000 to $+4000 \mathrm{~kg} \mathrm{ha}^{-1}$ (Neeteson \& Wadman, 1987).

Variability effects on the difference between $N_{E A P}$ and $N_{M E Y}$ are even more pronounced than those on $\mathrm{N}_{\text {MEY }}$. This conclusion shows that existing quantitative field data on the ways in which environmental standards can be met, suffer from the bias for homogeneity in selecting trial fields. Although the available evidence thus is a poor basis for statements about the current intensity of environmental problems in Dutch agriculture, the experiments of the past clearly indicate the direction for finding solutions: if variability on normal farmer fields can be reduced to the levels normally found on experimental fields the conflict between production and environmental targets will become less severe. During agricultural development in the past century major efforts have been made to increase field homogeneity by drainage, levelling, corrective fertilization of 'bad spots' and other means to adjust the 'hardware' for production. To meet environmental standards of $\mathrm{N}$ leaching such efforts have to be continued, with additional attention to the 'software' of distributing inputs which will mineralize in subsequent seasons. Field tests of the effects of variability predicted by the model are needed. 
Effects of spatial variability are considerably smaller if production targets are, say, $80 \%$ to $90 \%$ of $Y_{\max }$, as formulated for certain types of 'integrated' agriculture. For production targets well below $Y_{\max }$ within-field compensation is possible, relatively rich sites leading to increased production.

The model results indicate a number of ways to combine production and environmental targets:

1. Control variability in mineral-N supply in the soil. Major attention should be given to the spatial distribution of crop residues as the substrate for future mineralization. When crop residues are ploughed into the soil a considerable difference in the amount of residue per unit soil area can be observed. This pattern must lead to substantial variability of $\mathrm{N}_{\min }$ on the scale of the unit soil area. In grassland management, the considerable increase in heterogeneity of $\mathrm{N}_{\min }$ by urinating cattle can only be solved by applying a zero-grazing system or by accepting lower yields from heterogeneous plots. The technical target of a $10 \%$ coefficient of variation in fertilizer application rates appears sufficient in view of other existing sources of variation.

2. Measure $\mathbf{N}_{\min }$ as late as technically possible. Late measurements may increase the spatial correlation $\varrho_{1}$ between $\mathrm{N}_{\min }$ and subsequent mineralization and thus allow a finer tuning of fertilizer rates. Measurements of $\mathrm{N}_{\min }$ during the growing season may also reduce uncertainty because of year-to-year variation in mineralization.

3. Improve synchrony of mineralization and crop demand in the sense used here. Accumulating data on effects of food web composition on the rate of mineralization (de Ruiter et al., 1992) may be used in the future for guiding crop management to achieve a low value of $\alpha$.

4. Avoid a positive and try to obtain a negative spatial correlation between $\mathrm{N}_{\mathrm{F}}$ and $\mathrm{N}_{\mathrm{S}}$ by adjusting fertilizer rates patch-by-patch to available mineral $\mathrm{N}$ in the soil. Technical feasibility is restricted sofar to relatively coarse-grained patterns in large fields. When near-maximum yields are achieved, crop parameters are poor indicators of spatial patterns in mineral $\mathrm{N}$ supply. If some yield reduction is allowed, spatial patterns in $\mathrm{N}$ supply become evident and can in the future be taken into account.

5. Select crops with increased capacity for 'luxury consumption', provided that this has no negative effect on crop quality. Although the term indicates that $\lambda$ has usually been regarded as a negative characteristic, the present model shows that it has a positive effect on the difference between $\mathrm{N}_{\mathrm{EAP}}$ en $\mathrm{N}_{\mathrm{MEY}}$. In the longer run, higher $\lambda$ values will lead to greater spatial heterogeneity in $\mathrm{N}$ content of crop residues and hence of mineralization in the next season, counteracting the positive effect mentioned.

At a policy level, the fertilizer:produce price ratio is often discussed as an instrument to influence farmers' decisions on input use. In the standard case without variability, a doubling of the price ratio reduced $\mathrm{N}_{\mathrm{MEY}}$ by $17 \mathrm{~kg}$ from 95 to $78 \mathrm{~kg}$ $\mathrm{ha}^{-1}$ and a fourfold increase reduced it by $51 \mathrm{~kg}$ to $44 \mathrm{~kg} \mathrm{ha}^{-1}$. The difference with $\mathrm{N}_{\mathrm{EAP}}(34)$ is thus increased from +13 to +30 and +64 , respectively. As a doubling is considered to be a substantial change, the conclusion is often formulated that 
changing the price ratio is not very effective. For the 'standard' variability the effect of a two- or fourfold increase of the price ratio is more pronounced: $\mathrm{N}_{\mathrm{MEY}}$ is reduced by 31 and $73 \mathrm{~kg} \mathrm{ha}^{-1}$ from 118 to 87 and $45 \mathrm{~kg} \mathrm{ha}^{-1}$, respectively; for a doubled variability $\mathrm{N}_{\mathrm{MEY}}$ is reduced by 54 and $130 \mathrm{~kg} \mathrm{ha}^{-1}$ (from 189 to 135 and $59 \mathrm{~kg} \mathrm{ha}^{-1}$ ), respectively. The difference between $\mathrm{N}_{\mathrm{MEY}}$ and $\mathrm{N}_{\mathrm{EAP}}(34)$ changes from -26 to +5 and +47 for standard variability and from -166 to -102 and -26 , respectively. Provided that farmers apply $\mathrm{N}$ fertilizer according to the economic optimum rate for their conditions, we can see that a doubling of the price ratio will be much more effective in reducing fertilizer use and on meeting environmental standards on fields with higher spatial variability. Increased price ratios may provide a stimulus to tackle spatial variability in $\mathrm{N}$ supply and thus reduce leaching problems, without much effect on $\mathrm{Y}_{\mathrm{MEY}}$. This analysis suggests that modified price ratios deserve further analysis as a policy instrument.

Soil fertility research has in the past decade been focussed on the processes of soil-plant interaction for an 'average' plant as part of a crop field. Models based on these processses are, however, not a sufficient basis for agricultural applications, unless spatial heterogeneity on the field scale is accounted for. The model presented here may help to bridge this gap. In further extensions of this work, factors such as variability in water supply which induce variability in $\mathrm{Y}_{\max }$ may be incorporated.

\section{Acknowledgements}

Thanks are due to Ir P.J. van Erp (Netherlands Fertilizer Institute, Haren) and Drs P. Finke (Wageningen Agricultural University) for sharing unpublished data on variability of $\mathrm{N}_{\min }$ in the field and to Ir E.L.J. Verberne, Dr P.C. de Ruiter and Dr Ir P. de Willigen for critically reading the manuscript.

\section{References}

Bole, J.B. \& U.J. Pittman, 1976. Sampling Southern Alberta soils for N and P testing. Canadian Journal of Soil Science 56: 531-535.

Briggs, K.G., 1974. Soil sampling and soil uniformity for N, P and $\mathrm{K}$ in a small plot area. Canadian Journal of Soil Science 54: 115-117.

Cameron, D.R., M. Nyborg, J.A. Toogood \& D.H. Laverty, 1971. Accuracy of field sampling for soil tests. Canadian Journal of Soil Science 51: 165-175.

Curnow, R.N., 1973. A smooth population response curve based on an abrupt threshold and plateau model for individuals. Biometrics 29: 1-10.

Dahiya, I.S., K.C. Kersebaum \& J. Richter, 1984. Spatial variability of some nutrient constituents of an Alfisol from loess. I. Classical statistical analysis. Zeitschrift für Pflanzenernährung und Bodenkunde 147: 695-703.

Dahnke, W.C. \& R.A. Olson, 1990. Soil test correlation, calibration, and recommendation. In: R.L. Westerman (Ed.), Soil testing and plant analysis, p. 45-71. Soil Science Society of America, Madison, Wisc., USA.

Dilz, K. \& G.D. van Brakel, 1985. Effects of uneven fertiliser spreading - a literature review. Fertiliser Society London, Proceedings No $240,51 \mathrm{pp}$.

Greenwood, D.J., J.J. Neeteson \& A. Draycott, 1985. Response of potatoes to N fertilizer: quantitative relations for components of growth. Plant and Soil 85: 163-183.

Groot, J.J.R. \& E.L.J. Verberne, 1991. Response of wheat to nitrogen fertilization, a data set to 


\section{VAN NOORDWIJK AND W.P. WADMAN}

validate simulation models for nitrogen dynamics in crop and soil. Fertilizer Research 27: 349-383.

Hunt, J., W.Y. Ng, A. Barnes \& D.J. Greenwood, 1979. A rapid method for estimating nitratenitrogen concentrations in field soils. Journal of the Science of Food and Agriculture 30: 343-353.

Knittel, H. \& H. Fischbeck, 1979. Die Heterogenität des Nitratgehaltes in den Profilschichten einer Ackerbraunerde zu Beginn des Frühjahrs. Zeitschrift für Pflanzenernährung und Bodenkunde 142: 683-695.

Kolenbrander, G.J., 1968. Size and nature of the variability of the mineral nitrogen content in soil. Stikstof 12: 123-130.

Meirverne, M. van \& G. Hofman, 1989. Spatial variability of soil nitrate nitrogen after potatoes and its change during winter. Plant and Soil 120: 103-110.

Neeteson, J.J., 1990. Development of nitrogen fertilizer recommendations for arable crops in the Netherlands in relation to nitrate leaching. Fertilizer Research 26: 291-298.

Neeteson, J.J., 1992. The risk of nitrate leaching after application of nitrogen fertilizers to agricultural crops. In: D.C. Adriano (Ed.), Advances in Environmental Science, Groundwater Series, Springer, New York (in press).

Neeteson, J.J. \& W.P. Wadman, 1987. Assessment of economically optimum application rates of fertilizer on the basis of response curves. Fertilizer Research 12: 37-52.

Noordwijk, M. van, 1990. Synchronisation of supply and demand is necessary to increase efficiency of nutrient use in soilless horticulture. In: M.L. van Beusichem (Ed.), Plant Nutrition - Physiology and Applications, p. 525-531. Kluwer Academic Publishers, Dordrecht.

Noordwijk, M. van, 1992. Root position effectivity ratio, $R_{\text {per }}$, a simple measure of the effects of non-homogeneous root distribution on uptake of homogeneous resources. In: L. Kutschera (Ed.), Root Ecology and its Practical Application (in press).

Noordwijk, M. van \& P. de Willigen, 1986. Quantitative root ecology as element of soil fertility theory. Netherlands Journal of Agricultural Science 34: 273-281.

Noordwijk, M. van, J. Floris \& A. de Jager, 1985. Sampling schemes for estimating root density distribution in cropped fields. Netherlands Journal of Agricultural Science 33: 241-262.

Noordwijk, M. van, P. de Willigen, P.A.I. Ehlert \& W.J. Chardon, 1990. A simple model of P-uptake as a possible basis for P fertilizer recommendations. Netherlands Journal of Agricultural Science 38: 317-332.

Prins, W.H., K. Dilz \& J.J. Neeteson, 1988. Current recommendations for nitrogen fertilisation within the EEC in relation to nitrate leaching. Proceedings 276. The Fertilizer Society, London, $27 \mathrm{pp}$.

Richter, J., H. Nordmeyer \& K.Chr. Kersebaum, 1984. Zur Aussagesicherheit der $\mathrm{M}_{\min }$-Methode. Zeitschrift für Acker- und Pflanzenbau 153: 285-296.

Ris, J. \& J. Wolf, 1979. Sampling error of soil mineral $\mathrm{N}$ determined on arable soils. [In Dutch]. Institute for Soil Fertility, Haren, Nota 64, 15 pp.

Ruiter, P.C. de, J.C. Moore, K.B. Zwart, L.A. Bouwman, J. Hassink, J. Bloem, J.A. de Vos, J.C.Y. Marinissen, W.A.M. Didden, G. Lebbink \& L. Brussaard, 1992. Stimulation of nitrogen mineralization in belowground food webs of two winter wheat fields. Journal of Applied Ecology (in press).

Veen, B.W., M. van Noordwijk, P. de Willigen, F.R. Boone \& M.J. Kooistra, 1992. Root-soil contact of maize, as measured by a thin-section technique. III. Effects on shoot growth, nitrate and water uptake efficiency. Plant and Soil 139: 131-138.

White, R.E., R.A. Haigh \& J.H. Macduff, 1987. Frequency distributions and spatially dependent variability of ammonium and nitrate concentrations in soil under grazed and ungrzed grassland. Fertilizer Research 11: 193-208.

Willigen, P. de, 1991. Nitrogen turnover in the soil-crop system: comparison of fourteen simulation models. Fertilizer Research 27: 141-149.

Willigen, P. de \& M. van Noordwijk, 1987. Roots, plant production and nutrient use efficiency. Doctoral thesis, Wageningen Agricultural University, $282 \mathrm{pp}$.

Wit, C.T. de, 1953. A physical theory of fertilizer placement. Doctoral thesis, Wageningen Agricultural University, $71 \mathrm{pp}$. 